Military Technical College Kobry El-Kobbah, Cairo, Egypt

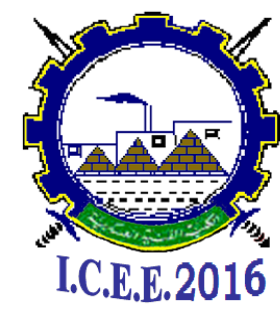

$8^{\text {th }}$ International Conference

on

Chemical \& Environmental

Engineering

$19-21$ April 2016

DRA-1

\title{
Design of Nuclear Radiation Meter and Its Utilization for Non- Destructive Determination of Areal Density of Carpets via Beta Particles Measurements
}

\author{
M.M. El-Dessouky*, H. Mosleh**, M. Alaa El-Din**, M.S. Adel-Rahman**
}

\begin{abstract}
The circuit of radiation meter is designed for determination areal thickness of carpets as a non-destructive test using beta particles measurement technology. The design is based on design of stabilized DC voltage for the operation of GM, junction transistor for normalizing the pulses of GM, programmable microprocessor for integration of the pulses, and monitor for obtaining the result of measuring. The collected electronic pulses were processed after programming the used microprocessor. The designed instrument gave good results for determination of areal density of carpets and has low power consumption. It was tested by beta particles emitted from Sr-90 man-made source. The source satisfies site security and human health. The system is simple to use. Linear relationship between logarithmic values of counting rates and areal thickness is obtained. This relationship is utilized for determination of the areal thickness of carpets and adjusting the amount of latex coating during the production.
\end{abstract}

Keywords: Determination of the areal thickness of carpets, Non-destructive test, nuclear measurement technology, Geiger Muller counter, Beta radiation, Sr-90 source, Programmable microprocessor.

*: BUE, Faculty of Engineering, Chem. Eng. Dep.

**: Oriental Weavers, Research Dep. $10^{\text {th }}$ of Ramadan City 


\author{
Military Technical College \\ Kobry El-Kobbah, \\ Cairo, Egypt
}

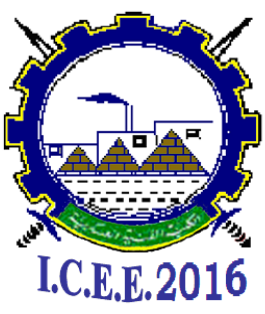

$8^{\text {th }}$ International Conference

on

Chemical \& Environmental

Engineering

19 - 21 April 2016

\section{Introduction}

The beta radiation measurements were based on data using GM detector and a programmable microprocessor. It gave good response directly and has low power consumption. It was tested for beta source from Sr-90 from the man-made source that satisfies site security and human health [1]. The GM array is used in photon low energy-level imaging [2]. The only requirements for radiation measurement by this type of detector are to have suitable stabilized DC voltage for working and how to measure the resulted pulses.

The radiation must have enough energy to penetrate the walls of the detector tube to create ion pairs in the gas. Radiation detectors designed for this type of radiation must be constructed with thin walls that allow the radiation to penetrate. Ion pairs produced from interaction of radiation with the gas of GM tube, accelerate toward their respective electrodes due to the high voltage potential. Secondary ions are produced due to the rapid movement of the initial ion pairs especially electrons towards the electrodes, so the entire sensitive volume of the tube is ionized (Townsend avalanche). The ions reaching electrodes are neutralized and produce the voltage pulse which will be measured by the electronic processing unit [3].

GM has high sensitivity and high efficiency for beta response entering the detector. GM is sensitive for the particles of low energy range. They are smaller in size than ionization chamber type detectors. GM counters are normally operated in the pulse mode. GM survey meters are widely used at very low radiation levels. GM detectors suffer from long dead times, ranging from tens to hundreds of milliseconds. For this reason, GM counters are not used when accurate measurements are required of count rates of more than a few hundred counts per second [4-5].

The absorption of radiation is characterized by the equation:

$$
\mathrm{I}=\mathrm{I}_{\mathrm{o}} \exp \left(-\mu_{\mathrm{m}} \mathrm{X}_{\mathrm{m}}\right) \& \quad \ln \mathrm{I}=\ln \mathrm{I}_{\mathrm{o}}-\mu_{\mathrm{m}} \mathrm{X}_{\mathrm{m}}
$$

where $I_{0}$ is the number of particles of radiation counted during a certain time duration without any absorber, $I$ is the number counted during the same time with areal thickness $x_{m}\left(\mathrm{~kg} \cdot \mathrm{m}^{-2}\right)$, and mass absorption coefficient $\mu_{\mathrm{m}}\left(\mathrm{m}^{2} . \mathrm{kg}^{-1}\right)[6-7)$.

The previous experience is utilized to choose the principal components of design after modifications and improvements [8]. The main components are DC stabilized power supply for GM, normalization of the pulses, and programmed microprocessor.

\section{Experimental}

Different proposed circuits are proposed and tested by simulating program till the optimum one is obtained and checked by the results of primary testing. Different GM tubes are tested 
Military Technical College

Kobry El-Kobbah, Cairo, Egypt

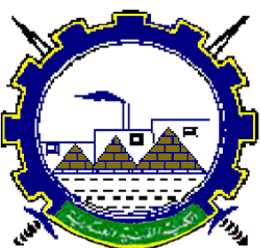

I.C.E.E.2016 $8^{\text {th }}$ International Conference

on

Chemical \& Environmental

Engineering

$19-21$ April 2016

till the optimum one of more repetitive measurements are obtained. The optimum GM was ZP-1400 at working operating voltage $560 \mathrm{~V}$. The optimum circuit is shown in figure (1).

The initial power supply transfers $220 \mathrm{AC} \mathrm{V}$ to stabilized $10 \mathrm{DC}$ V. The convertor transfers $10 \mathrm{DC} \mathrm{V}$ to adjusted operating voltage required for operation of GM, in the range of 5001000 DC V. The pulses obtained from GM in case of presence of beta source Sr-90, are normalized and junketed to the microprocessor by BC 237 transistor. The microprocessor ATMEGA328P is programmed to integrate the pulses from GM each 3 seconds and to display the values as average counting rate.

The carpets are made from pile of polypropylene fibers and weft of goat and warp from polyester waved by mechanical looms. After waiving process, the carpets are coated by latex SBR (Styrene butadiene Rubber) for fixation. The samples of carpets of different areal thicknesses are prepared. The areal thickness of the prepared samples is determined simply by determination of the area and weight. The results of areal densities are shown in table (1). The counting rate of Sr-90 source is determined for samples of the same carpets before and after coating by latex. The measurement was followed according to the following arrangement

Table (1): The areal thickness of the prepared samples

\begin{tabular}{|c|c|c|c|c|c|}
\hline Sample \# & $\begin{array}{c}\text { Dimensions } \\
\mathbf{( c m ~ x ~ c m ) ~}\end{array}$ & $\begin{array}{c}\text { Area } \\
\mathbf{( m}^{\mathbf{2}} \mathbf{)}\end{array}$ & $\begin{array}{c}\text { Weight } \\
\mathbf{( g )}\end{array}$ & $\begin{array}{c}\text { Areal } \\
\text { Thickness } \\
\mathbf{( g / \mathbf { m } ^ { 2 } )}\end{array}$ & $\begin{array}{c}\text { Areal } \\
\text { Thickness } \\
\mathbf{( k g / \mathbf { m } ^ { 2 }}\end{array}$ \\
\hline 1 & $50.3 \times 42.9$ & 0.2158 & 287.7 & 1333.18 & 1.333 \\
\hline 2 & $51.5 \times 38.5$ & 0.1983 & 340.3 & 1716.09 & 1.716 \\
\hline 3 & $37.7 \times 35.5$ & 0.1338 & 272.3 & 2035.13 & 2.035 \\
\hline 4 & $38.2 \times 33.1$ & 0.1264 & 311.3 & 2462.82 & 2.463 \\
\hline 5 & $37 \times 33$ & 0.1221 & 326.8 & 2676.49 & 2.676 \\
\hline 6 & $43 \times 36.5$ & 0.157 & 435.8 & 2775.8 & 2.776 \\
\hline 7 & $37 \times 32.5$ & 0.1203 & 355.6 & 2955.94 & 2.956 \\
\hline 8 & $43.5 \times 34.5$ & 0.1501 & 446.5 & 2974.68 & 2.975 \\
\hline 9 & $38.7 \times 35.6$ & 0.1378 & 421.5 & 3058.78 & 3.059 \\
\hline 10 & $39.3 \times 29.8$ & 0.1171 & 455.6 & 3890.69 & 3.891 \\
\hline
\end{tabular}

\section{Results and Discussion}

The average counting rate (I) of beta particles from Sr-90 source is determined with the areal thickness (d) of samples and shown in table (2). By plotting ln (I) against areal thickness (d) we obtained straight line as shown in figure (2). 
Military Technical College

Kobry El-Kobbah,

Cairo, Egypt

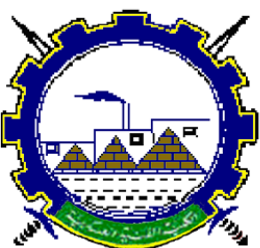

I.C.E.E.2016 $8^{\text {th }}$ International Conference

on

Chemical \& Environmental

Engineering

$19-21$ April 2016

Table (2): The average counting rate of beta particles from Sr-90 source after absorption in the prepared samples

\begin{tabular}{|c|c|c|c|}
\hline sample & I (counts / s) & In I (counts / s) & $\mathbf{d ~}\left(\mathbf{k g} / \mathbf{m}^{2}\right)$ \\
\hline 0 & $2641 \pm 25(0.95 \%)$ & 7.879 & 0.000 \\
\hline 1 & $2266 \pm 38(1.7 \%)$ & 7.726 & 1.333 \\
\hline 2 & $1906 \pm 90(4.7 \%)$ & 7.553 & 1.716 \\
\hline 3 & $1704 \pm 55(3.2 \%)$ & 7.441 & 2.035 \\
\hline 4 & $1409 \pm 45(3.2 \%)$ & 7.251 & 2.463 \\
\hline 5 & $1324 \pm 23(1.7 \%)$ & 7.188 & 2.676 \\
\hline 6 & $1213 \pm 67(5.5 \%)$ & 7.101 & 2.776 \\
\hline 7 & $1177 \pm 37(3.1 \%)$ & 7.071 & 2.956 \\
\hline 8 & $1078 \pm 21(1.9 \%)$ & 6.983 & 2.975 \\
\hline 9 & $1020 \pm 19(1.9 \%)$ & 6.928 & 3.059 \\
\hline 10 & $720 \pm 22(3.1 \%)$ & 6.579 & 3.891 \\
\hline
\end{tabular}

As shown from the figure (2), any unknown carpet can be put between the source and the detector, and by measuring (I) after absorption of beta particles, the thickness of carpet can be obtained. Good linear relationship is obtained with $\mathrm{R}^{2}=0.9911$.

The areal thickness of both carpet and latex (in $\mathrm{kg} / \mathrm{m}^{2}$ ) separately can be determined. Samples of carpets before and after latex coating are measured and the results as shown in table (3). Results show the difference of measurements in case of presence and absence of latex. This proves the suitability of designed instrument of determination of values of thickness of carpets as well as coated latex that it can be controlled during manufacture process. The instrument can be utilized for adjusting and controlling the coating process of latex during manufacture.

Table (3): Measurements of counting rate of beta particles from Sr-90 source for carpet samples before and after latex coating

\begin{tabular}{|c|c|c|c|c|c|}
\hline Sample & $\begin{array}{c}\text { (I) carpet } \\
\text { with latex }\end{array}$ & $\begin{array}{c}\mathrm{d} \\
\left(\mathrm{kg} / \mathrm{m}^{2}\right)\end{array}$ & $\begin{array}{c}\text { (I ) carpet } \\
\text { without } \\
\text { latex }\end{array}$ & $\begin{array}{c}\mathrm{d} \\
\left(\mathrm{kg} / \mathrm{m}^{2}\right)\end{array}$ & $\begin{array}{c}\text { Latex } \\
\text { thickness (d) } \\
\text { in }\left(\mathrm{kg} / \mathrm{m}^{2}\right)\end{array}$ \\
\hline 1 & $1405 \pm 56$ & 2.362 & $1380 \pm 55$ & 2.484 & 0.122 \\
\hline 2 & $2013 \pm 70$ & 1.639 & $1878 \pm 38$ & 1.794 & 0.155 \\
\hline 3 & $2350 \pm 69$ & 1.293 & $2223 \pm 78$ & 1.417 & 0.124 \\
\hline 4 & $2570 \pm 51$ & 1.092 & $2448 \pm 49$ & 1.201 & 0.109 \\
\hline 5 & $2405 \pm 48$ & 1.241 & $2276 \pm 68$ & 1.364 & 0.123 \\
\hline
\end{tabular}

The actual latex coating was in the same range determined by beta measurements. 


\author{
Military Technical College \\ Kobry El-Kobbah, \\ Cairo, Egypt
}

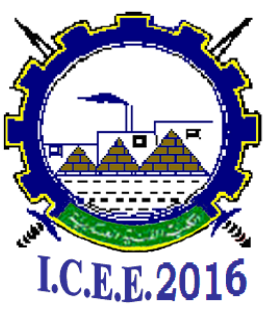

$8^{\text {th }}$ International Conference

Chemical \& Environmental Engineering

$19-21$ April 2016

\section{Conclusions}

The results are encouraging for determination of areal thickness of carpets $\left(\mathrm{kg} / \mathrm{m}^{2}\right)$ through use of beta particles measurements using GM counter and designed circuit instead of ionization chamber as detector that is used in mahlo GRAVIMAT FMI-12 instrument for the same object with simpler design. Moreover the high sensitivity of GM counter enables to use lower source activity of Sr-90 of range: 1-20 $\mu \mathrm{Ci}$ instead of using $20 \mathrm{mCi}$ in the noted instrument which is very important for security and health safety. The repeatability of measurements were acceptable since deviations of measurements were from $0.95-5.5 \%$ and good relationship between $\ln I$ and areal density with $\mathrm{R}^{2}=0.9911$.

For technological improvement and possibility of utilization of this instrument in the factory of production of carpets, excess work is required for obtaining more carpet samples with and without latex coating. Also trails are necessary to design connection circuit to computer more than microprocessor to utilize the possibilities of computer in accurate calculations and possibility of automatic control of coating process of latex. Moreover, design of software is required to obtain directly the weight of one square meter of carpets coated and non-coated directly from the results of beta absorption curves as a non-destructive test, and to utilize the instrument for automatic control of the optimum coating of latex during production.

The design is important for quality control of production of carpets and adjusting the latex coated. The national design of such instruments is very important for more future improvement and self dependence for maintenance and repair. Also utilization of such instruments enables not to buy very expensive instruments and save hard currency.

\section{References}

[1] M. A. A. Mashud, Md. Shamim Hossain, M. Nurul Islam, and M. S.Islam, Design and development of PC based data acquisition system for radiation measurement, I.J. Image, Graphics and Signal Processing, Vol. 7 (2013) 34-40.

[2] K.Mori, et al., Proton radiation damage experiment on P-channel CCD for an X-ray CCD camera onboard the ASTRO-H satellite, Nucl. Instr. and Methods in Phys. Res. A 731 (2013)160-165.

[3] G.F.Knoll, Chapter 7 Radiation Detection and Measurement, John Wiley \& Sons, New York 2005, pp 89 -126.

[4] G. Rajan, and J. Izewska, Medical Physics and Safety Section, Bhabha Atomic Research Centre, Radiation Monitoring Instruments, Chapter 4, Mumbai, Maharashtra, India 2001, pp 101- 121.

[5] O.M. Noor, Development of Energy Compensated Geiger Muller Detector Based on the T2416A Canberra CO. GM Detector, A Thesis submitted in Partial Fulfillment of the Requirements for the Degree of Master of Science, faculty of energy systems and nuclear science program university of Ontario Institute of Technology, 2013. 
Military Technical College Kobry El-Kobbah, Cairo, Egypt

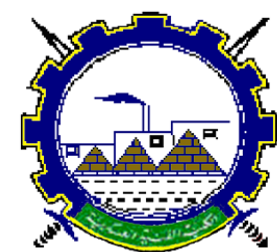

I.C.E.E.2016 $8^{\text {th }}$ International Conference on

Chemical \& Environmental

Engineering

$19-21$ April 2016

[6] A.Franklin, William Wilson and the Absorption of Beta Rays, Physics in Perspective, Vol.4 (2002) 40 -77.

[7] C.S. Mahajan, Mass attenuation coefficients of beta particles in elements, Sci. Res. Rep. , Vol. 2 (2) (2012)135 - 141.

[8] M. M. EL-Dessouky, The Technological Production of Portable Nuclear Radiation Meters, 7th ASAT Conf. 13-15 May, M.T.C, Cairo, 1997, 851-855. 
Military Technical College Kobry El-Kobbah, Cairo, Egypt

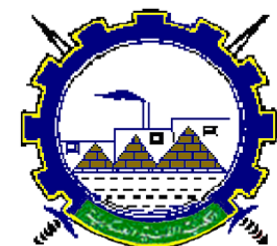

I.C.E.E.2016 $8^{\text {th }}$ International Conference on

Chemical \& Environmental Engineering

19-21 April 2016

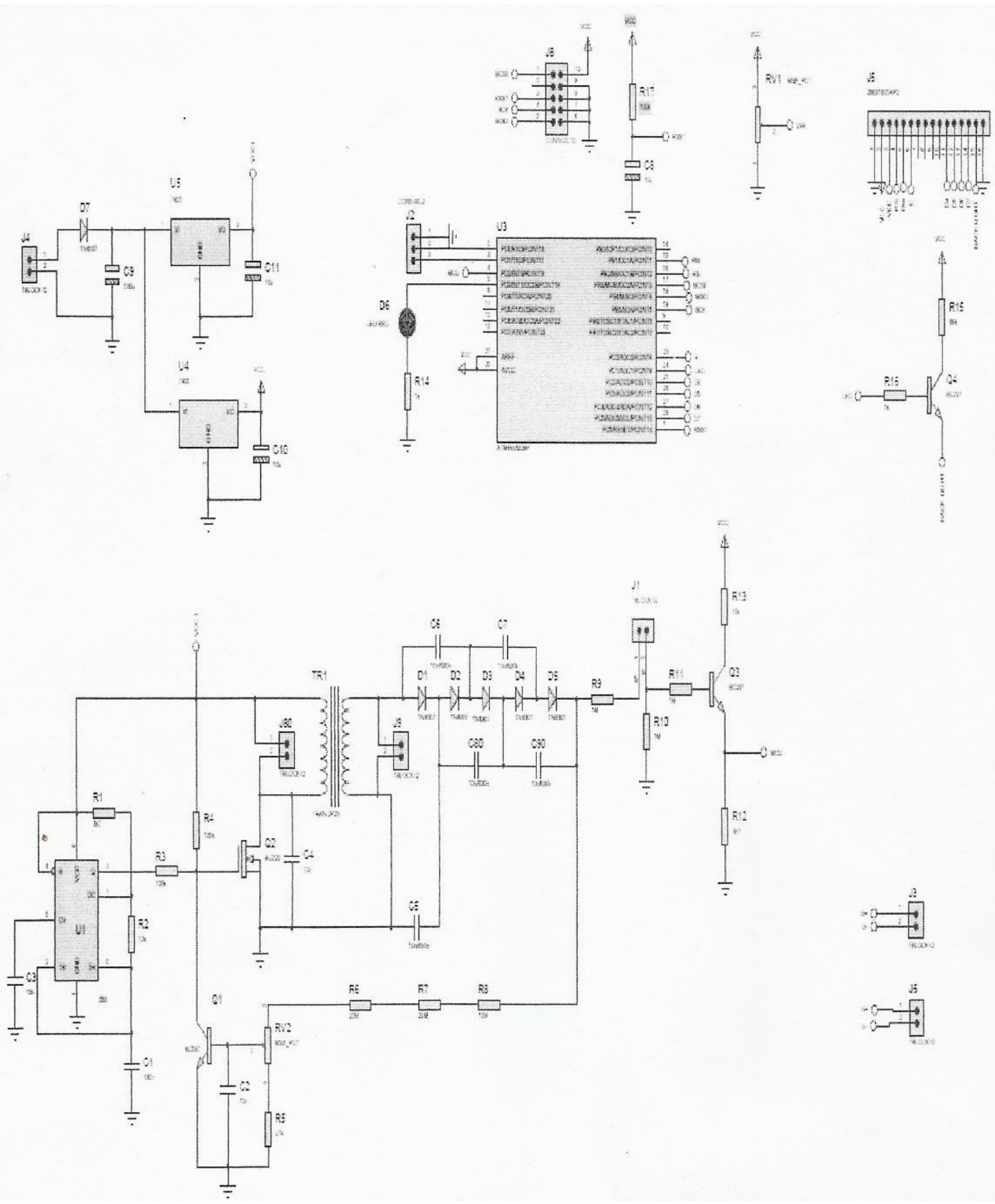

Figure (1): Circuit diagram of designed instrument. 
Military Technical College Kobry El-Kobbah, Cairo, Egypt

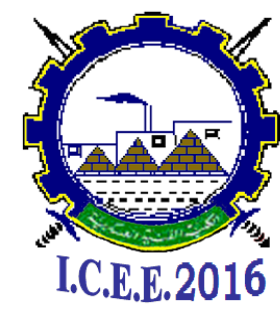

$8^{\text {th }}$ International Conference on

Chemical \& Environmental Engineering

19 - 21 April 2016

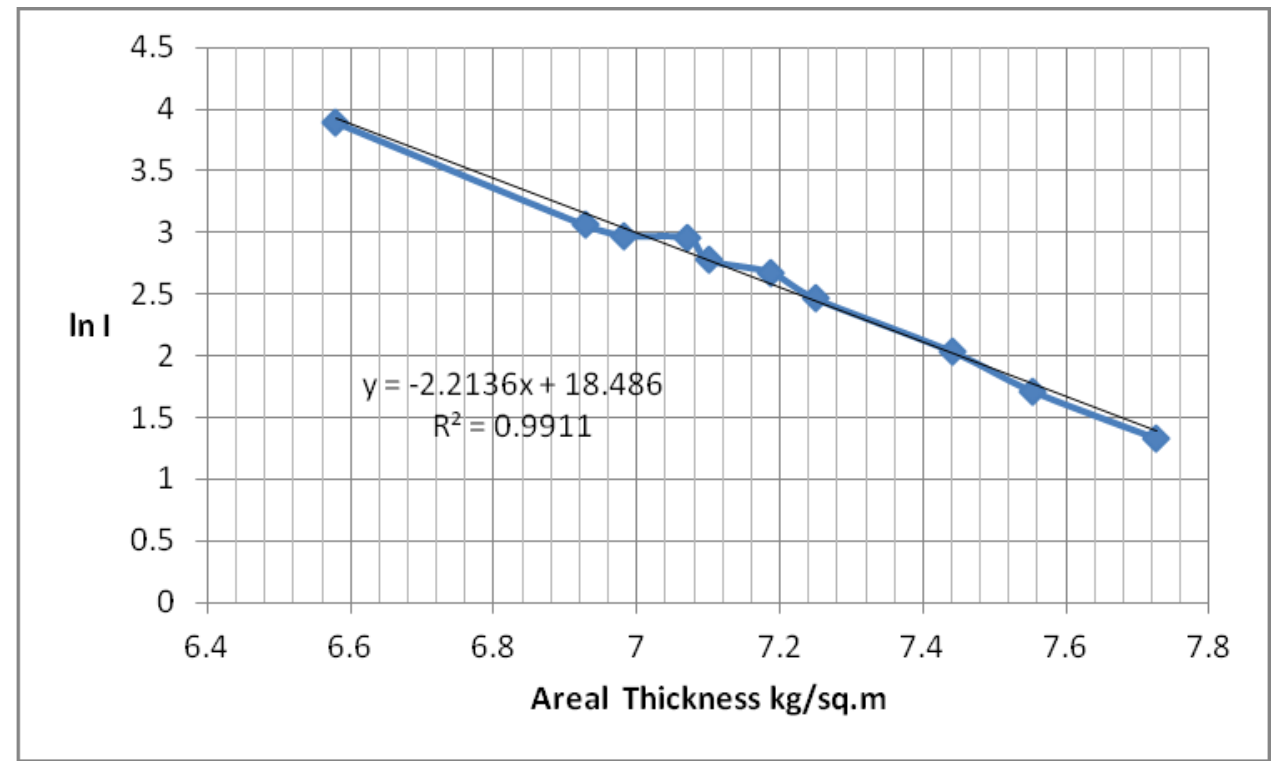

Figure (2): Relation between logarithmic value of counting rate of beta particles from Sr-90 source "In (I)" and areal thicknesses of carpets $\left(\mathrm{kg} . \mathrm{m}^{-2}\right)$

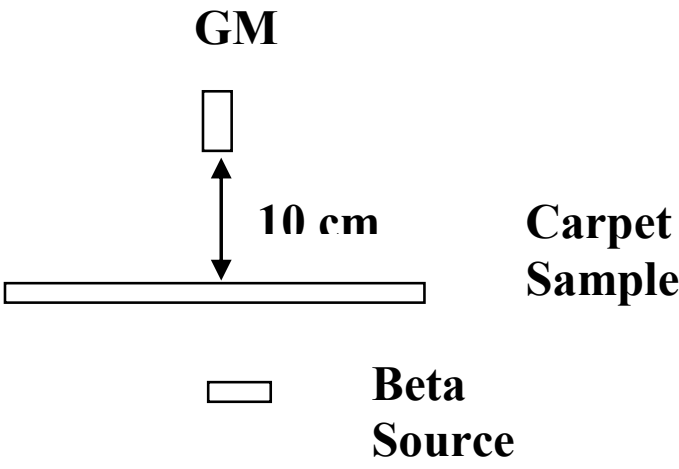

Figure (3): Technique used for measurements 